\title{
Salivary flow rate and xerostomia in patients with type I and II diabetes mellitus
}

\author{
Amineh Hoseini ${ }^{1}$, Ali Mirzapour ${ }^{2}$, Ali Bijani ${ }^{3}$, Atena Shirzad ${ }^{4}$
}

${ }^{1}$ Dental Student, Student Research Committee, Babol University of Medical Sciences, Babol, Iran

${ }^{2} \mathrm{MD}$, Endocrinologist, Babol, Iran

${ }^{3}$ MD, Social Determinants of Health Research Centre, Health Research Institute, Babol University of Medical Sciences, Babol, Iran

${ }^{4}$ DDS, MS, Oral Medicine, Assistant Professor, Department of Oral Medicine, Faculty of Dentistry, Babol University of Medical Sciences, Babol, Iran

\section{Type of article: Original}

\begin{abstract}
Background: Diabetes mellitus is one of the most prevalent metabolic diseases, with complications such as decreased salivary flow rate and xerostomia.

Objective: This study aimed to determine the salivary flow rate and xerostomia in type I and II diabetic patients in comparison with healthy controls.

Methods: This case-control study was performed on diabetic patients of a private office in Babol, Iran, between May 2015 and October 2016. This study involved two study groups (type I and II diabetes, with 40 in each group) and two control groups (control I and II, with 35 in each group) which were age- and sex-matched with the related study groups. They were all selected through simple sampling. Unstimulated whole saliva was collected through Navazesh method and the salivary flow rate was measured $(\mathrm{ml} / \mathrm{min})$. Xerostomia was evaluated via Fox's test. Moreover, the patients' data were recorded including age, sex, disease duration, type of diabetes, fasting blood glucose (FBG) and $\mathrm{HbA1C}$. The obtained data were statistically analyzed by using SPSS version 17. Independent-samples t-test, Chi-square, Pearson correlation and multiple comparison post-hoc tests were employed as appropriated. $\mathrm{p}<0.05$ was considered significant.

Results: The mean salivary flow rate in type I diabetics $(0.35 \pm 0.11 \mathrm{ml} / \mathrm{min})$ was lower than that in control I $(0.50 \pm 0.07 \mathrm{ml} / \mathrm{min})(\mathrm{p}=0.01)$. The same difference was observed between type II diabetics $(0.37 \pm 0.13 \mathrm{ml} / \mathrm{min})$ and control II groups $(0.47 \pm 0.11 \mathrm{ml} / \mathrm{min})(\mathrm{p}=0.01)$. No significant difference was observed in the salivary flow rate between type I and II diabetics $(\mathrm{p}=0.345)$. Furthermore, xerostomia was higher in type I $(2.70 \pm 2.50$, $1.17 \pm 1.60)$ and II $(2.65 \pm 2.20-1.62 \pm 1.50)$ diabetics compared with the related control groups $(\mathrm{p}=0.01),(\mathrm{p}=0.02)$.

Conclusion: Type I, II diabetic patients revealed lower salivary flow rate and higher xerostomia compared with healthy controls. The salivary flow rate and xerostomia had inverse correlation.

Keywords: Xerostomia, Salivary flow rate, Diabetes mellitus
\end{abstract}

\section{Introduction}

Diabetes mellitus is a metabolic disease which is characterized by chronic hyperglycemia. In type I diabetes, insulin secretion is absent due to the destruction of pancreatic beta cells. Type II diabetes is specified by the resistance of peripheral tissues to insulin and relative decrease in insulin secretion $(1,2)$. The prevalence of diabetes has multiplied worldwide within the recent decades, which has caused it to become an issue of public health, particularly in developing societies $(1,3)$. Long-term hyperglycemia results in broad systemic complications, namely, cardiovascular diseases, neuropathy, and nephropathy (4). Moreover, oral manifestations such as saliva secretion impairments, periodontitis, delayed wound healing, and burning mouth increase in diabetic patients. Glycemic

\section{Corresponding author:}

Assistant Professor Dr. Atena Shirzad, Department of Oral Medicine, Faculty of Dentistry, Babol University of Medical Sciences, Babol, Iran. Tel: +98. 1132291408, Mobile: +98. 9113553054 Email: Ats60dent@gmail.com

Received: January 08, 2017, Accepted: March 20, 2017, Published: September 2017

iThenticate screening: February 26, 2017, English editing: May 12, 2017, Quality control: August 20, 2017

This article has been reviewed / commented by three experts

(C) 2017 The Authors. This is an open access article under the terms of the Creative Commons Attribution-NonCommercialNoDerivs License, which permits use and distribution in any medium, provided the original work is properly cited, the use is non-commercial and no modifications or adaptations are made. 
control plays a key role in initiation and development of many signs and symptoms $(5,6)$. Reduced salivary flow rate and dry mouth cause dental caries, oral candidiasis, difficulty in swallowing and speaking; which, in turn, affects the oral health-related quality of life (7-9). Xerostomia is the subjective feeling of a patient describing dry mouth, which is, in fact, a symptom not a disease. It should be noted that complaints of oral dryness should not always be considered as salivary glands disorder, because xerostomia can also occur as a result of dehydration, oral sensory disturbances, psychological condition, and central cognitive alteration (1). In the above-mentioned cases which create false xerostomia, the salivary glands function normally. Reduced salivary secretion is the most important cause of true xerostomia. The flow rate of normal unstimulated saliva is $0.3-0.5 \mathrm{ml} / \mathrm{min}$. If it decreases to less than 0.1-0.2 $\mathrm{ml} / \mathrm{min}$, one would experience xerostomia (6). In true xerostomia, a malfunction occurs in salivation. It is accompanied by increased risk of oral mucosal lesions, oral infections and dental caries. Hence, it is quite important to correctly discern the true and the false xerostomia. Dentists play an imperative role in this context. The subjective xerostomia can be evaluated through various questionnaires; namely, Fox's test, which is a standard questionnaire whose reliability and validity has previously been proven (10). The salivary flow rate can also be objectively measured through sialometry. Studies on the salivary flow in diabetic patients have reported contradictory results $(2,3,8,9)$.Moreover, few studies have simultaneously assessed xerostomia and salivary flow in type I and II diabetic patients $(6,3)$. Thus, the current study was aimed at evaluating the subjective xerostomia and the salivary flow rate in type I and II diabetic patients, in comparison with healthy controls.

\section{Material and Methods}

This case-control study was performed in a private office in Babol, between May 2015 and October 2016 (Ethical Code: MUBABOL.REC.1394.278). Using simple random sampling method, 80 diabetic patients were enrolled including 40 cases of type I ( 15 males and 25 females) and 40 of type II (16 males and 24 females). Moreover, 70 healthy controls from entourages of patients were recruited in two subgroups as control I and control II, each consisiting of 35 sample cases. The sample size was determined based on previous studies (6). The inclusion criteria for being allocated to the study groups were having no other systemic disease than diabetes either type I or II for a minimum of 5 years (11), and having taken no other medication than blood glucose controlling medications within the 3 preceding months. Those included in the control I and II groups were healthy individuals who had normal fasting blood glucose (FBG) and their age and sex matched the type I and II groups, respectively. They had no systemic disease and used no medication. The exclusion criteria used for both groups were use of alcohol, smoking, pregnancy, history of radiotherapy, salivary gland disease, psychiatric disorder, presence of any oral mucosal lesion and wearing dentures. The study was completely explained to the patients and written informed consent was obtained. Oral examinations were done to ensure the absence of mucosal lesions and salivary gland enlargement. Demographic data, type of diabetes, disease duration, and the degree of FBG and $\mathrm{HbA} 1 \mathrm{C}$ were recorded. The participants in both study and control groups answered Fox's test on xerostomia. This test which is a standard questionnaire whose reliability and validity has previously been proven, consisted of ten questions with yes/no answers. Four positive answers out of ten were considered as positive xerostomia $(1,6,10)$. A single observer collected all the saliva samples from the subjects, to eliminate any chance of a bias. Then, unstimulated whole saliva was collected through Navazesh method. Saliva was collected from the patients in the morning between 9 am-12 am. The patients were asked to avoid eating, drinking, and brushing at least one hour before collecting saliva. While collecting saliva, the patient sat upright on a chair in a cool environment with head bent slightly forward. For 5 minutes, once each minute, the patient spat the whole secreted saliva directly into a graded tube. So, the salivary flow rate was measured in $\mathrm{ml} / \mathrm{min}$ (12). The obtained data were statistically analyzed by using SPSS software, version 17. Independent-samples t-test, Chi-square, Pearson correlation and multiple comparison post-hoc tests were employed as appropriated. $\mathrm{p}<0.05$ was considered significant.

\section{Results}

This study was carried out on 150 participants including ( 80 patients \& 70 controls), 40 patients with type I diabetes ( 15 men and 25 women), 40 patients with type II diabetes (16 men and 24 women), as well as two control groups including control I ( 35 subjects: 14 men and 21 women) and control II (35 subjects: 15 men and 20 women). Table 1 represents the mean $\pm \mathrm{SD}$ of age, disease duration, FBG, and HBA1C in each group. Table 2 displays the mean $\pm \mathrm{SD}$ of salivary flow rate and mean scores of Fox's test in study and control groups. It was observed that as HBA1C increased, the salivary flow rate decreased $(\mathrm{p}=0.044)$. There was a significant relation between the HBAlC and the mean scores of Fox's test $(\mathrm{p}=0.03)$. The salivary flow rate in type I diabetics was significantly lower compared to control I $(\mathrm{p}<0.01)$. Likewise, the salivary flow rate in type II diabetics was lower than that in control II $(\mathrm{p}<0.01)$ (Table 2). No significant difference was observed in the salivary flow rate between type I and II diabetics ( $\mathrm{p}=0.345$ ). Xerostomia was remarkably higher in type I diabetics than that in control I $(\mathrm{p}=0.01)$. It was the same in terms of 
type II diabetics and control II groups $(\mathrm{p}=0.02)$ (Table 2). No significant difference was noted in the mean scores of Fox's test between type I and II diabetics $(\mathrm{p}=0.81)$. However, xerostomia and salivary flow rate had inverse correlation; i.e., the higher the xerostomia was, the lower the salivary flow rate would be (Figure 1).

Table 1. The mean $\pm \mathrm{SD}$ of age, $\mathrm{HBA}_{1} \mathrm{C}$, Fasting Blood Glucose (FBG) and disease duration in diabetics and control groups

\begin{tabular}{|l|l|l|l|l|}
\hline Comparisons & Age (year) $($ mean \pm SD) & HBA1c $($ mean \pm SD) & FBG $^{1}($ mean \pm SD) & Disease duration (year) \\
\hline DM. I $^{2}$ & $31.05 \pm 6.80$ & $7.65 \pm 1.08$ & $190.20 \pm 49.20$ & $23.32 \pm 6.50$ \\
\hline DM.II & $30.55 \pm 7.90$ & $7.54 \pm 2.06$ & $183.52 \pm 61.13$ & $10.67 \pm 4.80$ \\
\hline Control I & $30.02 \pm 7.40$ & - & - & - \\
\hline Control II & $49.28 \pm 7.60$ & - & - & - \\
\hline
\end{tabular}

1: Fasting Blood glucose; 2: dibetes mellitus type I; 3: dibetes mellitus type II

Table 2. The mean $\pm \mathrm{SD}$ of salivary flow rate and total scores of Fox's test in diabetics and control groups

\begin{tabular}{|l|l|l|}
\hline Comparisons & Salivay flow rate $(\mathrm{ml} / \mathrm{min})(\mathrm{mean} \pm \mathrm{SD})$ & $\begin{array}{l}\text { mean scores of Fox's test } \\
(\mathrm{mean} \pm \mathrm{SD})\end{array}$ \\
\hline DM.I $^{1}$ & $0.35 \pm 0.11$ & $2.70 \pm 2.50$ \\
\hline Control I $^{2}$ & $0.50 \pm 0.07$ & $1.17 \pm 1.60$ \\
\hline p-value $^{2}$ & 0.01 & 0.01 \\
\hline DM.II $^{3}$ & $0.37 \pm 0.13$ & $2.65 \pm 2.20$ \\
\hline Control II $^{2}$ & $0.47 \pm 0.11$ & $1.62 \pm 1.50$ \\
\hline p-value $^{2}$ & 0.01 & 0.02 \\
\hline
\end{tabular}

1: dibetes mellitus type I; 2: The obtained data were statistically analyzed by using multiple comparison post-hoc tests. $\mathrm{p}<0.05$ was considered significant; 3 : dibetes mellitus type II

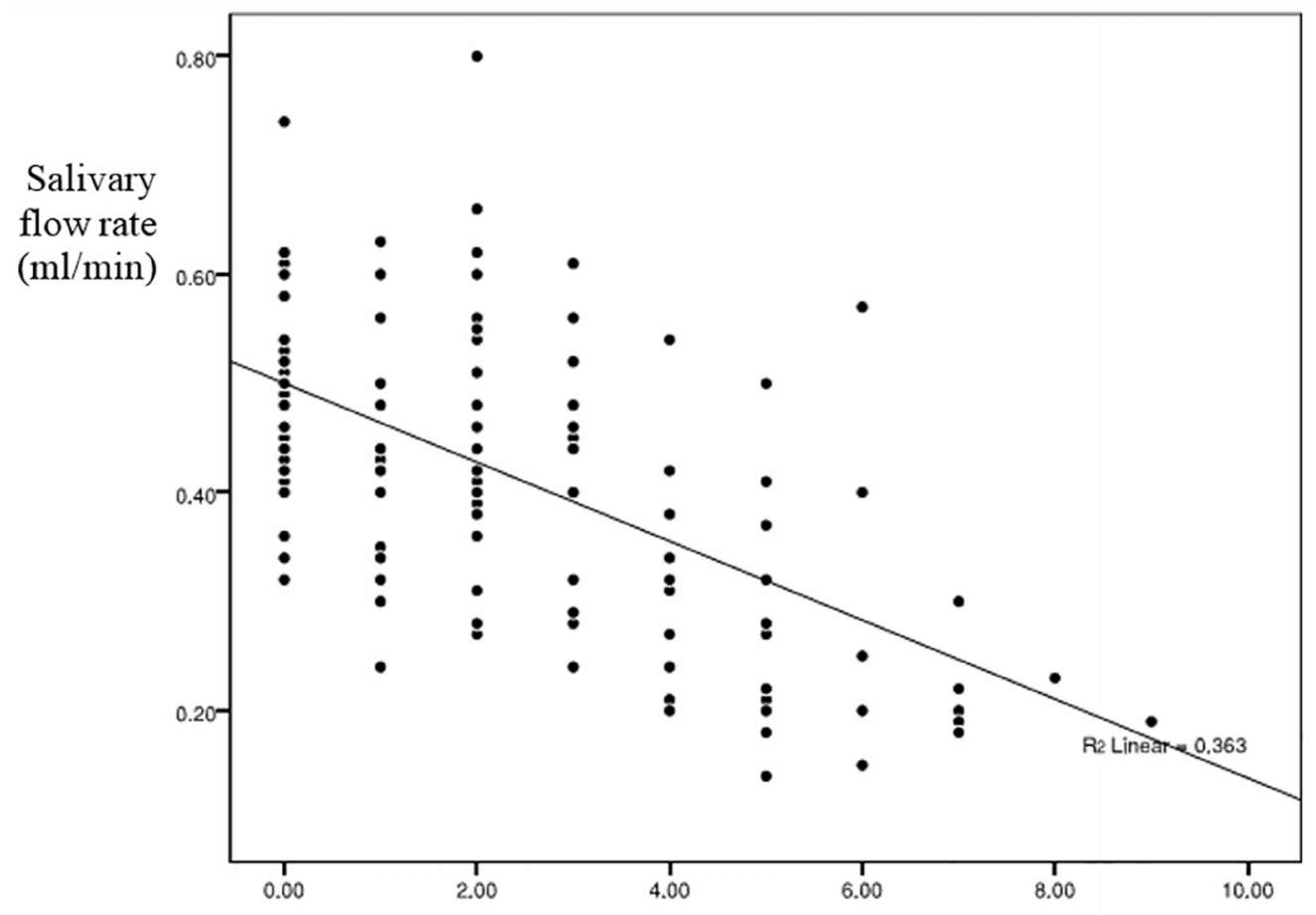

mean scores of Fox's test

Figure 1. Relationship between xerostomia and salivary flow rate

\section{Discussion}

Several studies have evaluated the salivary changes in diabetic patients; however, few studies have assessed xerostomia as well as salivary flow rate $(3,8,9,13)$. The present study investigated the salivary flow rate and xerostomia in type I and II diabetic patients. The findings indicate a significant decrease of the salivary flow rate in 
both type I and II diabetes. While some studies have already confirmed the same findings $(3,14)$, there are investigations which reported no obvious difference in the salivary flow rate between type I and II diabetic patients and healthy individuals $(6,15)$. Such a contradiction can be attributed to the differences in saliva collecting methods (stimulated or unstimulated), the time of collecting, the patient's conditions and position at the time of collecting, and having no age- and sex-matching between the control and study groups. In order to prevent bias in the current study, the control groups were congruent with the study groups concerning age and sex. So, the maximum possible conformity was considered between the study and control group. Furthermore, the samples in the study groups had only diabetes, and no other systemic disease. Nor did those in the control group. Saliva was collected through the standard and repeatable method of spitting. Additionally, unstimulated saliva was also studied. Because unstimulated salivary gland function is the predominant state, this greatly influences overall oral comfort and protection of the oral cavity (1). Among the several reasons which contribute to the decreased salivary flow rate in diabetes, lies the fact that following the hyperglycemia and glucosuria, body fluids are more excreted, and subsequently, secretion of saliva is reduced. Additionally, pathologic changes in the structure of salivary glands neuropathy of the sympathetic and parasympathetic system, and microvascular disorders, disrupt saliva production. It must be noted that the weaker the diabetes is controlled, the more drastic these changes would be $(6,16)$. The present study did not clarify which type of diabetes more reduced the saliva secretion; nor was a considerable difference found between the two types of diabetes concerning the reduced salivary flow rate. It was in line with the results obtained in a similar investigation (6). However, it is noteworthy that the mean age of patients in type II is generally higher; consequently, higher autonomic and peripheral neuropathies as well as more age-related vascular changes are observed in this group. On the other hand, the disease duration is longer in patients with type I diabetes; hence, they more deeply experience the complications of hyperglycemia such as paresthesia, xerostomia, and polyuria. The degree of disease control is quite an important factor in both types of diabetes $(1,17)$. Concerning the variety of intervening factors in each type of diabetes, and the fact that it cannot be predicted which factor is more influential; it can be stated that the current study did not find any considerable difference in the salivary flow rate. With respect to the current findings, it can be announced that xerostomia in both type I and II was higher than that in control I and II. As previously mentioned, few investigations have been performed on xerostomia. A research employed a xerostomia subjective test and confirmed higher xerostomia in patients with type II diabetes (16). In another study which made use of Fox's test, xerostomia was reported to be higher in type I diabetic patients (18). Another study reported no significant difference in xerostomia between type I and II diabetic patients in comparison with healthy controls. In order to justify their findings, they claimed that type II diabetic patients would less feel the xerostomia probably due to aging, peripheral neuropathies, baroreceptors, and oral mucosa changes $(7,8,19)$. There are different indices to assess the subjective xerostomia. The present study made use of the satndard Fox's test, whose validity and reliablity has been already approved (10). We observed no significant difference in xerostomia between the two types of diabetes. It was clear there was not a significant relation between xerostomia and type of diabetes. However, xerostomia might be - not only related to the salivary flow rate, but also to the organic and inorganic content of the saliva (14). This study found that the lower the salivary flow rate was, the higher the xerostomia was in diabetic patients. Xerostomia can indicate decreased salivary flow. It can greatly help faster diagnosis of reduced salivary flow in diabetic patients and early control of salivary flow complications. Diabetes affects not only the quantity, but also the quality of saliva (14, 20-23). Thus, it can be stated that reduced salivary flow on one side, and changes in the components of saliva on the other side can create xerostomia. The current study was only a quantitative assessment of saliva rate. Among the limitations of this study was assessing neither the contents of saliva nor patient selection from the private office. Therefore, further studies are suggested to evaluate the quality of saliva in addition to its quantity.

\section{Conclusions}

The results of this article showed that the salivary flow rate decreases in patients with diabetes type I and II in comparison with healthy individuals, and diabetic patients experience more severe xerostomia. But due to the limitations of this article, futhure investigations with larger sample sizes are needed to evaluate the quality and quantity of saliva.

\section{Acknowledgments:}

This article is extracted from the thesis by Amineh Hosseini with the number 9441430. The authors would like to express their appreciation to the Deputy of Research and Technology of Babol University of Medical Sciences for their financial support of the study. 


\section{Conflict of Interest:}

There is no conflict of interest to be declared.

\section{Authors' contributions:}

All authors contributed to this project and article equally. All authors read and approved the final manuscript.

\section{References:}

1) Glick M. Burket's Oral Medicine, 12th ed: PMPH-USA; 567-83.

2) American Diabetes Association. Diagnosis and classification of diabetes mellitus. Diabetes Care. 2011; 34 Suppl 1: S62-9. doi: 10.2337/dc11-S062. PMID: 21193628, PMCID: PMC3006051.

3) López-Pintor RM, Casañas E, González-Serrano J, Serrano J, Ramírez L, de Arriba L, et al. Xerostomia, hyposalivation, and salivary flow in diabetes patients. Journal of Diabetes Research. 2016; 2016: 1-16. doi: $10.1155 / 2016 / 4372852$.

4) Kuzuya T, Nakagawa S, Satoh J, Kanazawa Y, Iwamoto Y, Kobayashi M, et al. Report of the Committee on the classification and diagnostic criteria of diabetes mellitus. Diabetes Res Clin Pract. 2002; 55(1): 65 85. PMID: 11755481.

5) Manfredi M, McCullough MJ, Vescovi P, Al-Kaarawi ZM, Porter SR. Update on diabetes mellitus and related oral diseases. Oral Dis. 2004; 10(4): 187-200. doi: 10.1111/j.1601-0825.2004.01019.x. PMID: 15196139 .

6) Malicka B, Kaczmarek U, Skośkiewicz-Malinowska K. Prevalence of xerostomia and the salivary flow rate in diabetic patients. Adv Clin Exp Med. 2014; 23(2): 225-33. PMID: 24913113.

7) Chavez EM, Taylor GW, Borrell LN, Ship JA. Salivary function and glycemic control in older persons with diabetes. Oral Surg Oral Med Oral Pathol Oral Radiol Endod. 2000; 89(3): 305-11. PMID: 10710454.

8) Chávez EM, Borrell LN, Taylor GW, Ship JA. A longitudinal analysis of salivary flow in control subjects and older adults with type 2 diabetes. Oral Surg Oral Med Oral Pathol Oral Radiol Endod. 2001; 91(2): 166-73. doi: 10.1067/moe.2001.112054. PMID: 11174593.

9) Lin CC, Sun SS, Kao A, Lee CC. Impaired salivary function in patients with noninsulin-dependent diabetes mellitus with xerostomia. J Diabetes Complications. 2002; 16(2): 176-9. PMID: 12039402.

10) Fox PC, van der Ven PF, Sonies BC, Weiffenbach JM, Baum BJ. Xerostomia: evaluation of a symptom with increasing significance. J Am Dent Assoc. 1985; 110(4): 519-25. PMID: 3858368.

11) Adler AI, Stevens RJ, Manley SE, Bilous RW, Cull CA, Holman RR. Development and progression of nephropathy in type 2 diabetes: the United Kingdom Prospective Diabetes Study (UKPDS 64). Kidney Int. 2003; 63(1): 225-32. doi: 10.1046/j.1523-1755.2003.00712.x. PMID: 12472787.

12) Navazesh M. Methods for collecting saliva. Ann N Y Acad Sci. 1993; 694: 72-7. doi: 10.1111/j.17496632.1993.tb18343.x. PMID: 8215087.

13) Panchbhai AS, Degwekar SS, Bhowte RR. Estimation of salivary glucose, salivary amylase, salivary total protein and salivary flow rate in diabetics in India. J Oral Sci. 2010; 52(3): 359-68. doi: 10.2334/josnusd.52.359. PMID: 20881327.

14) Bakianian Vaziri P, Vahedi M, Mortazavi H, Abdollahzadeh Sh, Hajilooi M. Evaluation of salivary glucose, IgA and flow rate in diabetic patients: a case-control study. J Dent (Tehran). 2010; 7(1): 13-8. PMID: 21998770, PMCID: PMC3184719.

15) Karjalainen KM, Knuuttila ML, Käär ML. Relationship between caries and level of metabolic balance in children and adolescents with insulin-dependent diabetes mellitus. Caries Res. 1997; 31(1): 13-8. PMID: 8955988.

16) Carda C, Mosquera-Lloreda N, Salom L, Gomez de Feraris ME, Peydro A. Structural and functional salivary disorders in type 2 diabetic patients. Med Oral Patol Oral Cir Bucal. 2006; 11(4): 309-14. PMID: 16816810 .

17) Little JW, Falace DA, Miller CS, Rhodus NL. Dental Management of the Medically Compromised Patients. 8th. St. Louis; 2013: 219-40.

18) Moore PA, Guggenheimer J, Etzel KR, Weyant RJ, Orchard T. Type 1 diabetes mellitus, xerostomia and salivary flow rates. Oral Surg Oral Med Oral Pathol Oral Radiol Endod. 2001; 92(3): 281-91. doi: 10.1067/moe.2001.117815. PMID: 11552145.

19) Ben-Aryeh H, Serouya R, Kanter Y, Szargel R, Laufer D. Oral health and salivary composition in diabetic patients. J Diabetes Complications. 1993; 7(1): 57-62. PMID: 8481552. 
20) Yavuzyilmaz E, Yumak Ö, Akdoğanli T, Yamalik N, Özer N, Ersoy F, et al. The alterations of whole saliva constituents in patients with diabetes mellitus. Aust Dent J. 1996; 41(3): 193-7. doi: 10.1111/j.18347819.1996.tb04855.x. PMID: 8768645.

21) Expert Committee on the Diagnosis and Classification of Diabetes Mellitus. Report of the expert committee on the diagnosis and classification of diabetes mellitus. Diabetes Care. 2003; 26 Suppl 1: S5-20. PMID: 12502614.

22) Mandel ID. The diagnostic uses of saliva. J Oral Pathol Med. 1990; 19(3): 119-25. doi: 10.1111/j.16000714.1990.tb00809.x. PMID: 2187975.

23) Newrick P, Bowman C, Green D, O’Brien I, Porter S, Scully C, et al. Parotid salivary secretion in diabetic autonomic neuropathy. Journal of Diabetic Complications. 1991; 5(1): 35-7. doi: 10.1016/08916632(91)90008-D. 